Available online at GSC Online Press Directory

GSC Advanced Research and Reviews e-ISSN: 2582-4597, CODEN (USA): GARRC2

Journal homepage: https://www.gsconlinepress.com/journals/gscarr

(RESEARCH ARTICLE)

\title{
Patient awareness on stroke fast track in primary care center
}

\author{
Jiravittayaporn Keawalin ${ }^{1}$, Bosittipichet Tatree ${ }^{1}$ and Leesri Thanakamon ${ }^{2, *}$ \\ ${ }^{1}$ Department of Social Medicine, Phra Nakhon Si Ayutthaya Hospital 46/1 U-Thong Rd. Pratoochai sub-district Phra \\ Nakhon Si Ayutthaya district Phra Nakhon Si Ayutthaya 13000 Thailand. \\ ${ }^{2}$ Department of Community Health Nursing, Institute of Nursing, Suranaree University of Technology 111 University \\ Avenue Suranaree Subdistrict, Muang Nakornratchasima Province 30000, Thailand.
}

Publication history: Received on 01 March 2020; revised on 06 March 2020; accepted on 09 March 2020

Article DOI: https://doi.org/10.30574/gscarr.2020.2.3.0017

\begin{abstract}
Stroke is a crucial public disease. Even though there is a service called stroke fast track, a number of patients still cannot be provided with rt-PA (recombinant tissue plasminogen alteplase), in time. The objective of this study is to evaluate the awareness of those who are at risk of having stroke. The sample group is chosen from the patients at Family Practice Center in Phranakorn Sri Ayuthaya Province. The findings indicate that from the total number of 346 participants, $94.8 \%$ of them have known the term "stroke". However, only $11.6 \%$ of them have known the term "stroke fast track", and $50 \%$ of this group reported that this term has been introduced to them by public health officers. The key factor (statistic value is $\mathrm{p}<0.05$ ), which contributes to their awareness of stroke, is education level. Meanwhile, the main factors (statistic value is $\mathrm{p}<0.05$ ) that contributes to their awareness of a within-3-hour time length required in receiving a treatment, are age and education level. It indicates the participants with under 60 years old (adj. OR 2.08 [95\%CI 1.06, 4.07) and with High School Certificate or Vocational Diploma (adj. OR 4.41 [95\%CI 1.15, 16.93]) have a better awareness of this matter. It can be concluded from the findings that although the majority of participants are familiar with the term, "stroke", they still lack an awareness of stroke fast track.
\end{abstract}

Keywords: Stroke; Stroke Fast Track; Awareness; Family Practice Center

\section{Introduction}

Stroke is a significant world's public health issue. World Stroke Organization (WSO) reported that stroke is the leading cause of death as 80 million people worldwide had this disease, and 50 million suffered from paralysis, a common outcome of a stroke. This accounted for $62.5 \%$ of world's population [1].

In Thailand, stroke was reported as the second most fatal non-infectious disease, coming after cancer in 2016 [2]. Statistics recorded by Public Health Department revealed that the rates of mortality per a hundred thousand people between 2012 and 2016 were 31.7\%, 35.9\%, 43.3\% and 48.7\% respectively, and it is projected to rise in the upcoming years [3]. Hence, it is apparent that stroke is the leading cause of death for world's population as well as Thai residents.

Currently, a treatment of acute stroke was proved to provide a 50\% opportunity to cure patients with thrombosis successfully. The treatment is to give a patient recombinant tissue plasminogen alteplase (rt-PA) via their vein within 270 minutes after any unusual symptoms occurs [4]. Therefore, many hospitals provide a special service called "stroke fast track" in order to assist the patients to be given rt-PA more rapidly. Phranakorn Sri Ayuthaya Hospital had 444,483 and 549 stroke patients between 2016 and 2019 respectively. Meanwhile, a number of patients who could access stroke fast tract and get rt-PA without a prior prescription are 30, 18 and 27 from 2016 to 2019 respectively. Stroke fast tract is provided in the emergency room of Phranakorn Sri Ayuthaya Hospital. The average time before a patient can receive

\footnotetext{
${ }^{*}$ Corresponding author: Leesri Thanakamon
}

Copyright (C) 2020 Author(s) retain the copyright of this article. This article is published under the terms of the Creative Commons Attribution Liscense 4.0. 
rt-PA is 74.26 and 65 minutes. However, it is found that although stroke fast track was available, there were some patients who could not come and get the treatment in time. Thus, a researcher is interested in studying about patient's awareness of stroke and stroke fast track, and the sample group is patients from Family Practice Center in Phranakorn Sri Ayuthaya Province, Thailand.

\section{Methodology}

\subsection{Objective}

To study about patient's awareness of stroke and stroke fast track at Family Practice Center in Phranakorn Sri Ayuthaya Province, Thailand.

\subsection{Research Design and Processes}

This study is a descriptive research, and the participants of study are 346 patients who receive health service at Family Practice Center in Phranakorn Sri Ayuthaya Hospital between August to November 2019. The finding is calculated by using the formula, $\mathrm{n}=\mathrm{NZ}^{2} /\left(4 \mathrm{Ne}^{2}+\mathrm{Z}^{2}\right)$. To illustrate, $\mathrm{n}$ is sample size and $\mathrm{Z}$ is standard normal deviation set at $95 \%$ confidence level $(Z=1.96)$. e is acceptable sampling error expressed as a proportion 0.05 .

Inclusion criteria is that a participant must be over 20 years old and be diagnosed with high blood pressure, diabetes, dyslipidemia and/or heart disease. Exclusion criteria is that a participant must have never suffered from stroke before.

The study tool is a questionnaire called "an awareness of stroke fast track of people at risk in community", published by associate professor Nomjit Nualnet. The questionnaire can be divided into two parts. The first part contains personal questions, including gender, age, marital status, education, occupation and chronic medical issues. For the second part, there were the total of 16 questions, and the participants are questioned about their information access to stroke and stroke fast track as well as their awareness of stroke, stroke fast track, its symptoms and first aid process. The questionnaire can be answered by ticking a mark or writing down an answer. After giving an approval, each participant is interviewed by a researcher, and after the interview, they are also provided with the basic information of stroke and stroke fast track.

\subsection{Data Analysis}

The data is analyzed by a computer program called SPSS, and it is analyzed into descriptive statistics, such as figures, percentage, average number, standard deviation and relation analysis between different factors which contribute to an awareness of stroke fast track, by using Multiple Logistic Regression Analysis. This is presented with Adjusted OR (ORadj) and the confidence level is at $\mathrm{p}$-value $<0.05$

\subsection{Right to Protection and Research Ethics}

This study has been approved by the committee of research ethics regarding to human study in Phranakorn Sri Ayuthaya Hospital. (The number of projects: 019/2562 signed at August 14, 2019.

\section{Results}

\subsection{General Information}

From the total number of 346 participants, the majority of them (63.9\%) were females. The average age is $61.50 \pm 10.05$ years old, and Body Mass Index (BMI) is $28.76 \pm 29.33 \mathrm{~kg} / \mathrm{m}^{2}$. It is found that 268 of them (77.5\%) are married. Moreover, 216 of participants (53.2\%) hold primary school certificate, and 174 of them (50.3\%) are employed. Regarding to chronic health issues, 290 of them (83.8\%) have high blood pressure. 266 (76.9\%), 131 (37.9\%) and 11 (3.2\%) of them have dyslipidemia, diabetes, and heart disease respectively. A small number of participants who have other chronic diseases are also found. In addition, there are 179 participants who have two chronic diseases, accounting for $51.7 \%$. (see Table 1) 
Table 1 General Information $(n=346)$

\begin{tabular}{|c|c|c|}
\hline General & Number (Persons) & Percentage \\
\hline \multicolumn{3}{|l|}{ Sex } \\
\hline Male & 125 & 36.1 \\
\hline Female & 221 & 63.9 \\
\hline \multicolumn{3}{|l|}{ Age } \\
\hline$<60$ years old & 124 & 35.8 \\
\hline$>60$ years old & 222 & 64.2 \\
\hline \multicolumn{3}{|l|}{$($ mean $\pm \mathrm{SD}=61.50 \pm 10.05)$} \\
\hline \multicolumn{3}{|l|}{ Body Mass Index (kg. /m²) } \\
\hline$<23.0$ & 74 & 21.4 \\
\hline$\geq 23.0$ & 272 & 78.6 \\
\hline \multicolumn{3}{|l|}{ Status } \\
\hline Single & 18 & 5.2 \\
\hline Married & 268 & 77.5 \\
\hline Separated & 60 & 17.3 \\
\hline \multicolumn{3}{|l|}{ Education } \\
\hline None & 13 & 3.8 \\
\hline Primary school & 216 & 62.4 \\
\hline Secondary school / Certificated & 86 & 24.8 \\
\hline Bachelor degree and above & 31 & 9.0 \\
\hline \multicolumn{3}{|l|}{ Occupation } \\
\hline No / Volunteer & 172 & 49.7 \\
\hline Working & 174 & 50.3 \\
\hline \multicolumn{3}{|l|}{ Disease } \\
\hline Hypertension & 290 & 83.8 \\
\hline Hyperlipidemia & 266 & 76.9 \\
\hline Diabetes & 131 & 37.9 \\
\hline Heart Disease & 11 & 3.2 \\
\hline Others & 15 & 4.3 \\
\hline \multicolumn{3}{|l|}{ Chronic disease/Risk factors } \\
\hline 1 disease & 86 & 24.9 \\
\hline 2 diseases & 179 & 51.7 \\
\hline$>2$ diseases & 81 & 23.4 \\
\hline
\end{tabular}

\subsection{Information regarding stroke and stroke fast tract}

The findings show that 328 participants (94.8\%) have known about stroke, and 227 participants (69.2\%) said that they have learned about this disease from other sources such as from their family or community members who have stroke as well as from electronic source. However, only 40 participants (11.6\%) said that they have known about stroke fast 
track, and the majority of them have been introduced to this service by public health officers and other sources (family members or neighbors) (See Table 2).

Table 2 Awareness of "Stroke Fast Track"

\begin{tabular}{|c|c|c|}
\hline & $\begin{array}{l}\text { Number } \\
\text { (Persons) }\end{array}$ & Percentage \\
\hline \multicolumn{3}{|l|}{ Have you ever herd "Stroke Disease"? } \\
\hline Ever & 328 & 94.8 \\
\hline Never & 18 & 5.2 \\
\hline \multicolumn{3}{|l|}{ Sources $(n=328)$} \\
\hline Television/Radio & 124 & 37.8 \\
\hline Suggestions from health personal & 59 & 18.0 \\
\hline News/Journal & 20 & 6.1 \\
\hline Brief let/Brochure & 9 & 2.7 \\
\hline Others & 227 & 69.2 \\
\hline \multicolumn{3}{|l|}{ Have you ever herd "Stroke Fast Track"? } \\
\hline Ever & 40 & 11.6 \\
\hline Never & 306 & 88.4 \\
\hline \multicolumn{3}{|l|}{ Sources $(n=40)$} \\
\hline Television/Radio & 9 & 22.5 \\
\hline Suggestions from health personal & 20 & 50.0 \\
\hline News/Journal & 1 & 2.5 \\
\hline Brief let/Brochure & 1 & 2.5 \\
\hline Others & 13 & 32.5 \\
\hline \multicolumn{3}{|c|}{ Perception of Stroke disease's warning signs } \\
\hline Never & 69 & 19.9 \\
\hline Weakness / Difficult to walk & 146 & 42.2 \\
\hline Facial Paralysis & 71 & 20.5 \\
\hline Difficult to speak & 17 & 4.9 \\
\hline Headache & 68 & 19.7 \\
\hline Dizziness & 86 & 24.9 \\
\hline Numbness & 87 & 25.1 \\
\hline Blurred Vision & 10 & 2.9 \\
\hline Convulsion & 6 & 1.7 \\
\hline Nausea Vomiting & 4 & 1.2 \\
\hline \multicolumn{3}{|c|}{ First Aid for Persons with warning signs of Stroke } \\
\hline No information & 22 & 6.4 \\
\hline Refer to hospital & 262 & 75.7 \\
\hline Massage & 34 & 9.8 \\
\hline
\end{tabular}




\begin{tabular}{lll}
\hline & $\begin{array}{l}\text { Number } \\
\text { (Persons) }\end{array}$ & Percentage \\
\hline Rest & 12 & 3.5 \\
Alternative Medication & 5 & 1.5 \\
Waiting within 24 hours & 1 & 0.3 \\
Call to Physician & 2 & 0.6 \\
Others & 8 & 2.3 \\
Time management for caring stroke patients before refer & & \\
$<3$ hrs & 271 & 78.3 \\
$>3$ hrs & 75 & 21.7 \\
Opinion with your stroke risk factors & & \\
Risks (n=212) & 212 & 61.3 \\
$\quad$ Underlying disease & 130 & 61.3 \\
Family history & 5 & 2.4 \\
Normally occurrence & 30 & 14.2 \\
Others (Headache/Dizziness, Stress, Aging status, no exercise, & 47 & 22.2 \\
and Diet) & & \\
No risks (n=134) & 134 & 38.7 \\
Chronic disease but no symptoms & 103 & 76.9 \\
Drug adherence, and normally exercise & 15 & 19.7 \\
Healthy & 7 & 9.2 \\
$\quad$ No stress & 5 & 6.6 \\
None of family history & 4 & 5.3 \\
\hline
\end{tabular}

The three key symptoms of stroke, which suggest that a patient should be sent to stroke fast track, are a sudden weakness of arm and/or leg on either one or two sides of the body, a sudden numbness of face and trouble speaking. The first, second and third symptom can be identified by 146 (20.5\%), $71(20.5 \%)$ and 17 (4.9\%) participants respectively. However, it is found that 69 participants (19.9\%) cannot identify any of these symptoms.

Regarding to the assistance of those who display the stroke symptoms, it is found that 262 participants (75.7\%) can correctly answer that the patients must be sent to hospital immediately, but there were 22 participants (6.4\%) do not know how to assist a stroke patient. For an awareness of the critical time length to send a patient to a hospital, it is found that 271 participants (78.3\%) can correctly identify the time length according to stroke fast track's official guideline.

Regarding to the likeliness of having a stroke, it is found that even though all participants have high blood pressure, diabetes and/or dyslipidemia, which make them more prone to suffer from a stroke, 134 of them (38.7\%) are not convinced that they are at risk of having stroke (See Table 2).

\subsection{Information regarding the relationship between factors and the awareness of stroke}

After the analysis, it is found that the factor that related to patient's awareness of stroke, having statistical significance at 0.05 , is education level, being Primary Certificate (adj. OR 5.24 [95\%CI 1.15, 23.87]), High School Certificate or Vocational Diploma (adj. OR 14.14 [95\%CI 1.85, 108.21]) and Undergraduate Degree and higher (adj. OR 9.37 [95\%CI $1.78,113.35$ ) (See Table 3). 
Table 3 Factors related to the awareness of Stroke fast tract

\begin{tabular}{|c|c|c|c|c|}
\hline & \multicolumn{2}{|c|}{$\begin{array}{l}\text { Ever to hear Stroke fast } \\
\text { track }\end{array}$} & \multirow{2}{*}{$\begin{array}{l}\text { adj. OR } \\
(95 \% \mathrm{CI})\end{array}$} & \multirow{2}{*}{ p-value } \\
\hline & $\begin{array}{l}\text { Ever } \\
(n=328)\end{array}$ & $\begin{array}{l}\text { Never } \\
(n=18)\end{array}$ & & \\
\hline \multicolumn{5}{|l|}{ Sex } \\
\hline Male & $119(36.3)$ & $6(33.3)$ & 1 & \\
\hline Female & 209 (63.7) & $12(66.7)$ & $1.12(0.34,3.67)$ & 0.848 \\
\hline \multicolumn{5}{|l|}{ Age } \\
\hline$<60$ years old & $119(36.3)$ & $5(27.8)$ & $1.12(0.32,4.00)$ & 0.858 \\
\hline$>60$ years old & 209 (63.7) & $13(72.2)$ & 1 & \\
\hline \multicolumn{5}{|l|}{ Body Mass Index (kg. /m²) } \\
\hline$<23.0$ & $69(21.0)$ & $5(27.8)$ & $0.76(0.24,2.42)$ & 0.646 \\
\hline$\geq 23.0$ & $259(79.0)$ & $13(72.2)$ & 1 & \\
\hline \multicolumn{5}{|l|}{ Status } \\
\hline Single & $16(4.9)$ & $2(11.1)$ & 1 & \\
\hline Married & 258 (78.7) & $10(55.6)$ & $3.93(0.72,21.38)$ & 0.113 \\
\hline Separated & $54(16.5)$ & $6(33.3)$ & $1.63(0.24,10.91)$ & 0.613 \\
\hline \multicolumn{5}{|l|}{ Education } \\
\hline None & $10(3.0)$ & $3(16.7)$ & 1 & \\
\hline Primary school & $204(62.2)$ & $12(66.7)$ & $5.24(1.15,23.87)$ & $0.032 *$ \\
\hline Secondary school/Certificated & $84(25.6)$ & $2(11.1)$ & $14.14(1.85,108.21)$ & $0.011^{*}$ \\
\hline Bachelor degree & $30(9.1)$ & $1(5.6)$ & $9.37(1.78,113.35)$ & $0.047^{*}$ \\
\hline \multicolumn{5}{|l|}{ Occupation } \\
\hline None/Volunteer & $162(49.4)$ & $10(55.6)$ & 1 & \\
\hline Working & $166(50.6)$ & $8(44.4)$ & $1.10(0.35,3.46)$ & 0.875 \\
\hline \multicolumn{5}{|l|}{ Disease } \\
\hline Hypertension & $274(83.5)$ & $16(88.9)$ & $0.64(0.13,3.24)$ & 0.591 \\
\hline Hyperlypidemia & $253(77.1)$ & $13(72.2)$ & $1.84(0.53,6.36)$ & 0.339 \\
\hline Diabetes & $125(38.1)$ & $6(33.3)$ & $0.78(0.25,2.46)$ & 0.673 \\
\hline Heart disease & $10(3.0)$ & $1(5.6)$ & $0.63(0.06,6.42)$ & 0.697 \\
\hline Others & $14(4.3)$ & $1(5.6)$ & $0.64(0.07,5.79)$ & 0.693 \\
\hline \multicolumn{5}{|l|}{ Chronic disease and Risk factors } \\
\hline 1 disease & $82(25.0)$ & $4(22.2)$ & 1 & \\
\hline 2 diseases & $168(51.2)$ & $11(61.1)$ & $0.75(0.23,2.41)$ & 0.623 \\
\hline$>2$ disease & $78(23.8)$ & $3(16.7)$ & $1.27(0.28,5.85)$ & 0.761 \\
\hline
\end{tabular}

3.4. Information regarding the relationship between factors and the awareness of a within-3-hour time length required in receiving a stroke treatment from stroke fast track

After the analysis, it is found that age, having statistical significance at 0.05 , is the main factor that related to patient's awareness of a within-3-hour time length required in receiving a stroke treatment. Those aged under 60 (adj. OR 2.08 $[95 \%$ CI 1.06, 4.07) have a better awareness of this matter. Another main factor is the education level, being High School Certificate or Vocational Diploma (adj. OR 4.41 [95\%CI 1.15, 16.93]) (See Table 4). 
Table 4 Factors related to perceptions of Stroke's fast track in 3 hours

\begin{tabular}{|c|c|c|c|c|}
\hline & \multicolumn{2}{|l|}{$\begin{array}{l}\text { Perception } \\
\text { management }\end{array}$} & \multirow[b]{2}{*}{$\begin{array}{l}\text { adj. OR } \\
(95 \% \mathrm{CI})\end{array}$} & \multirow[b]{2}{*}{ p-value } \\
\hline & $\begin{array}{l}\text { Perceived } \\
\text { within } 3 \text { hrs } \\
(n=271)\end{array}$ & $\begin{array}{l}\text { No } \\
\text { Perceived } \\
\text { within } 3 \text { hrs } \\
(n=75)\end{array}$ & & \\
\hline \multicolumn{5}{|l|}{ Sex } \\
\hline Make & $98(36.2)$ & $27(36.0)$ & 1 & \\
\hline Female & $173(63.8)$ & $48(64.0)$ & $1.19(0.65,2.18)$ & 0.567 \\
\hline \multicolumn{5}{|l|}{ Age } \\
\hline$<60$ years old & $106(39.1)$ & $18(24.0)$ & $2.08(1.06,4.07)$ & $0.033^{*}$ \\
\hline$>60$ years old & $165(60.9)$ & $57(76.0)$ & 1 & \\
\hline \multicolumn{5}{|l|}{ Body Mass Index (kg. /m²) } \\
\hline$<23.0$ & $52(19.2)$ & $22(29.3)$ & $0.57(0.31,1.05)$ & 0.072 \\
\hline$\geq 23.0$ & $219(80.8)$ & $219(80.8)$ & 1 & \\
\hline \multicolumn{5}{|l|}{ Status } \\
\hline Single & $12(4.4)$ & $6(8.0)$ & 1 & \\
\hline Married & $214(79.0)$ & $54(72.0)$ & $2.47(0.81,7.51)$ & 0.112 \\
\hline Separated & $45(16.6)$ & $15(20.0)$ & $2.37(0.66,8.46)$ & 0.184 \\
\hline \multicolumn{5}{|l|}{ Education } \\
\hline None & $8(3.0)$ & $5(6.7)$ & 1 & \\
\hline Primary school & $164(60.5)$ & $52(69.3)$ & $2.34(0.70,7.85)$ & 0.168 \\
\hline Secondary school/Certificated & $75(27.7)$ & $11(14.7)$ & $4.41(1.15,16.93)$ & $0.031^{*}$ \\
\hline Bachelor & $24(8.9)$ & $7(9.3)$ & $1.82(0.42,7.87)$ & 0.425 \\
\hline \multicolumn{5}{|l|}{ Occupation } \\
\hline None/Volunteer & $131(48.3)$ & $41(54.7)$ & (ref.) & \\
\hline Working & $140(51.7)$ & $34(45.3)$ & $0.96(0.53,1.74)$ & 0.881 \\
\hline \multicolumn{5}{|l|}{ Disease } \\
\hline Hypertension & $228(84.1)$ & $62(82.7)$ & $1.10(0.53,2.31)$ & 0.792 \\
\hline Hyperlipidemia & $204(75.3)$ & 62 (82.7) & $0.67(0.32,1.41)$ & 0.295 \\
\hline Diabetes & 105 (38.7) & $26(34.7)$ & $0.88(0.47,1.63)$ & 0.676 \\
\hline Heart Disease & $7(2.6)$ & $4(5.3)$ & $0.61(0.16,2.40)$ & 0.481 \\
\hline Others & $13(4.8)$ & $2(2.7)$ & $1.86(0.39,8.78)$ & 0.433 \\
\hline \multicolumn{5}{|l|}{ Chronic disease } \\
\hline 1 disease & $70(25.8)$ & $16(21.3)$ & (ref.) & \\
\hline 2 diseases & $136(50.2)$ & $43(57.3)$ & $0.72(0.38,1.37)$ & 0.322 \\
\hline$>2$ diseases & $65(24.0)$ & $16(21.3)$ & $0.93(0.43,2.01)$ & 0.851 \\
\hline
\end{tabular}




\section{Discussion}

According to the study, it is found that several participants have heard a term, "stroke", but only $11.6 \%$ of them are familiar with a term, "stroke fast track". This corresponds with the findings of previous studies [5,6,14], indicating that stroke fast track is not commonly known by the public. The majority of them have been introduced to this service by public health officers and other sources (family members or neighbors). This is different from other studies [7] as their samples have learned about stroke from television, and following by from medical staffs and relatives/neighbors. This might result from the fact that the sample of this study mostly consists of elderly people who usually get information from public health officers and neighbors, rather than electronic sources.

About the factors regarding to the awareness of stroke, the findings of this study correspond with the studies of Huang [8], Marx [9] and Pandian [10] as it reveals that those who are highly educated are more likely to have a better awareness of stroke. However, it is found in this study that gender is not a key factor, which does not correspond with earlier studies. In those studies, it is found that women pay less attention on stroke than men do [11]. The difference might result from the facts that in these days, stroke can be found in people with all genders, and in fact, it is a leading cause of death among females [2]. Regarding to the age, it is found that the participants aged less than 60 have more awareness of stroke than their older counterparts do, and this corresponds with the studies of Lundelin [12] and Hickey [13] which found that elderly people have lower awareness of stroke.

Regarding to the factor related to the awareness of a within-3-hour time length required in receiving a stroke treatment, it is found that the participants aged less than 60 have more awareness of this matter. This corresponds with the study of Hickey [13] which found that elderly people have lower awareness of stroke as well as of a critical time length required in receiving a treatment. In addition, it is found that other chronic diseases, other risks of having stroke, are not significantly related to the awareness of a critical time length required in receiving a treatment from stroke fast track.

Nevertheless, from this study, it is found that there are a number of participants who do not know terms, like "stroke" and "stroke fast track". This might result from those terms are quite academic. Therefore, before publicizing the locals about stroke, it might be beneficial to study what terms they commonly use in the community. For example, some participants do not know stroke, but they have seen paralysis or semi-paralysis before. To acknowledge this difficulty might assist in having the locals to understand about the disease more easily.

In addition, from the study of the relationship between factors and awareness of stroke and of a within-3-hour time length in receiving a treatment, it is found that those aged less than 60 have more awareness of this matter. In other words, it is evident that elderly people, who are more at risk of having stroke, have lower awareness of this matter. Therefore, more campaigns should be launched to publicize information regarding stroke and its treatment to as many elderly people and their care providers as possible, so these senior residents can get a treatment from stroke fast track in time.

\section{Conclusion}

In Family Practice Center of Phranakorn Sri Ayuthaya Hospital, those who are prone to have stroke are patients with high blood pressure, diabetes dyslipidemia and/or heart disease. It is found that the majority of participants are familiar with stroke, but merely a small proportion of them aware of stroke fast track.

The findings of this study could beneficial for the hospital in planning their strategy and boosting the number of patients who can receive rt-PA within a critical time length. This will increase their chance of successful recovery and decrease the rate of paralysis as well as pressure of health care issues on family and society.

A further suggestion is that a researcher may compare between the patients who can get a treatment within a critical time length and those who cannot. Also, they can study about a care provider who can send a patient within a critical time length to identify what contributing factors are. 


\section{Compliance with ethical standards}

\section{Acknowledgments}

I express my profound thanks to the professors under the project of Family Practice and all Family Practice officers of Phranakorn Sri Ayuthaya Hospital for providing necessary information and their support in completing this study. I also express my gratitude to all participants for the willingness to spend time on completing the questionnaires.

\section{Disclosure of conflict of interest}

The authors declared no potential conflicts of interest with respect to the research, authorship, and or publication of this article.

\section{Statement of ethical approval}

As this study involves human subject, it has been approved by the committee of research ethics regarding to human study in Phranakorn Sri Ayuthaya Hospital, Thailand (The number of projects: 019/2562 signed at August 14, 2019)

\section{Statement of informed consent}

This study involves information about any individual such as survey, interview. The informed consent was obtained from all individual participants included in the study.

\section{References}

[1] World Stroke Day. (2018). Retrieved https://www.world-stroke.org/world-stroke-day-campaign.

[2] The committees of Annual Yearly Reports, Non-Communicable disease Control Department, Ministry of Public Health, Thailand. Bangkok: Graphic and design Publishing, (2018).

[3] International Health Policy Program. Report of Disability-Adjusted Life Years: DALYs, 2017. Nonthaburi: The Graphic System Company; 2017.

[4] Ackerson T, Adeoye OM, Brown M, Demaerschalk BM, Hoh B and Leslie-mazwi TM. (2018). AHA / ASA Guideline Guidelines for the Early Management of Patients with Acute Ischemic Stroke, 46-99.

[5] Nomjit Nualnetr, Sasiwimon Wannapong and Sakeeyah Khama. (2015). Perception of Stroke Fast Track among Risk Persons in Community. Srinakarind Medical Journal, 30 (1), 57-63.

[6] Kanjanasri Singphoo, Patcharin Auntri, Arakran Sangmeekun and Somsak Tiemkao. Knowledge and Perception of Stroke Fast Track or "270 minutes". North-Eastern Thai Journal Neuroscience, 2556, 28(4), 315-319.

[7] Wachira Chanabutra. (2016). Knowledge Risks and Warning Signs of Stroke: Case study of one Weaving Factory in Mahasarakrm Province. Mahasarakarm: Mahasarakarm University.

[8] Huang Y, Xie RM, Lu M, Cai YF, Guo JW and Miao XL. (2007). Effect evaluation for comprehensive treatment of acute stage of stroke. Journal of Chinese integrative medicine, 5(3), 276-281.

[9] Marx JJ, Gube C, Faldum A, Kuntze H, Nedelmann M, Haertle B, Dieterich M and Eicke BM. (2009). European Journal of Neurology, V.3, 16(5), 612-618.

[10] Pandian JD, Jaison A, Deepak SS, Kalra G, Shamsher S and Lincoln DJ. (2005). Public awareness of warning symptoms, risk factors, and treatment of stroke in northwest India, 36(3), 644-648.

[11] Fogle CC, Oser CS, Troutman TP, McNamara M, Williamson AP and Keller M. (2008). Public education strategies to increase awareness of stroke warning signs and the need to call 911. Journal of Public Health Management and Practice, 14(3), 17-22.

[12] Lundelin K, Graciani A, García-Puig J, Guallar-Castillón P, Taboada JM and Rodríguez-Artalejo F. (2012). Knowledge of Stroke Warning Symptoms and Intended Action in Response to Stroke in Spain: A Nationwide Population-Based Study. Cerebrovasc Dis, 34(2), 161-168.

[13] Hickey A, Holly D, McGee H, Conroy R and Shelley E. (2012). International journal of stroke: official journal of the International Stroke Society, 7(4), 298-306. 
[14] Travis LH, Flemming KD, Brown RD Jr, Meissner I, McClelland RL and Weigand SD. (2003). Awareness of stroke risk factors, symptoms, and treatment is poor in people at highest risk. Journal of Stroke and Cerebrovascular Diseases, 12(5), 221-227.

\section{How to cite this article}

Jiravittayaporn K, Bosittipichet T and Leesri T. (2020). Patient awareness on stroke fast track in primary care center GSC Advanced Research and Reviews, 2(3), 18-27. 